\title{
RBEP
}

\section{Las competencias de comunicación en el inicio de la lectoescritura}

Javier González García

http://dx.doi.org/10.1590/S2176-6681/335613105

\section{Resumen}

El artículo se centra en la evolución de los procesos de construcción conjunta del conocimiento escritor entre una maestra y sus alumnos cuando resuelven colectivamente diversas tareas planteadas desde el enfoque constructivista y significativo del lenguaje escrito. El análisis parte de un estudio longitudinal durante los dos primeros cursos de Educación Preescolar, grabando en video doce tríadas de alumnos en cada trimestre. La investigación se centra en como los niños construyen sus propias ideas sobre la escritura a partir de la experiencia que van teniendo y del contacto más directo y guiado que aporta la escuela. Para ello, aportamos distintas secuencias discursivas que muestran como el niño va adoptando diferentes estrategias. Desde esta perspectiva analizamos el papel del maestro como guía de sus alumnos, promoviendo el aprendizaje en su zona de desarrollo próximo de tal forma que aportará ayudas contingentes con el nivel cognitivo del alumno; según aumente el nivel del alumno mayor será la responsabilidad concedida a éste.

Palabras clave: lectoescritura; discusión; observación; constructivismo social; educación básica. 


\section{Resumo}

\section{As habilidades de comunicação no início da alfabetização}

O artigo aborda a evolução dos processos de construção conjunta de conhecimento de escrita entre uma professora e seus alunos quando resolvem, coletivamente, diversas tarefas provenientes do enfoque construtivista e significativo da linguagem escrita. A análise parte de um estudo longitudinal nos dois primeiros anos do ensino pré-escolar, sendo filmadas doze tríades de alunos a cada trimestre. A investigação foca na forma como as crianças constroem suas próprias ideias sobre a escrita a partir da experiência que vão adquirindo e do contato mais direto e orientação fornecida pela escola. Para isso, fornecemos diferentes sequências discursivas que mostram como a criança adota diferentes estratégias. A partir dessa perspectiva, analisamos o papel do professor como orientador de seus alunos, promovendo a aprendizagem em sua zona de desenvolvimento proximal de forma que contribua de acordo com o nível cognitivo do aluno. Quanto maior o nível do aluno, maior será a responsabilidade que deverá ser concedida a ele.

Palavras-chave: alfabetização; discussão; observação; construtivismo social; educação básica.

\section{Abstract \\ Communication skills in early literacy}

The article focuses on the evolution of the processes of co-construction of knowledge between a teacher and her pupils, when they collectively solve various tasks arising from the constructivist approach and meaningful written language. The analysis is based on a longitudinal study during the first two years of early childhood education, in which twelve triads of students were videotaped each trimester. The research focuses on how children construct their own ideas about writing through the experience they acquire and the more direct contact and guidance provided by the school. Therefore, we provided different discursive sequences that show how the child adopts different strategies. From this perspective, we analyze the teacher's role as a guide to students, in order to promote learning in their zone of proximal development and contribute to the according cognitive level of the student. The higher the student's level, the greater the responsibility that should be granted to him/her.

Keywords: literacy; discussion; observation; social constructivism; basic education. 


\section{Introducción}

Desde algunas perspectivas, la escritura es una destreza que permite transcribir lo oral mediante signos visibles, no obstante veremos que para la mayor parte de los planteamientos esta postura no se mantiene, ya que lo escrito tiene una dimensión distinta del oral (Álvarez, 2009). Así, podemos apreciar que desde la perspectiva cognitiva la escritura es un conjunto de procesos cognitivos y lingüísticos que nos permite elaborar un texto, y que para los autores que se sitúan en una posición sociocultural, el lenguaje escrito se entiende como un instrumento cultural que está influido por los ámbitos en los que se produce, por los usos que se hace de él y las funciones que tiene (Arroyo; Matienzo, 2011). A lo largo del artículo, la idea que defendemos es que es imposible entender el lenguaje escrito sin considerar que éste se produce en unas actividades reales que pueden ser de distinta índole: académicas, científicas o cotidianas. Escribir es un proceso complejo en el que están implicados no solamente el conocimiento que el sujeto tenga del tema sino otros aspectos determinantes como: a quién se dirige el mismo, qué tipo de género se va a desarrollar, cuáles son las metas que persigue el escritor, qué tipo de lenguaje se va a utilizar, como se va a organizar el texto (Frade, 2009). Todo esto presenta una considerable demanda cognitiva al escritor, ya que estos elementos están presentes de forma simultánea durante la construcción del texto (Diuk, 2007).

Las posiciones socioculturales surgen a principios de los años 80. La escritura pasa a concebirse como una actividad eminentemente social y comunicativa. La escritura es un instrumento cultural del cual el niño se apropiará mediante la participación en sucesos alfabetizados. La base de los estudios socioculturales es la teoría de Vygotsky (1995). Para este autor, el mecanismo fundamental del desarrollo cultural es el de interiorización de las interacciones sociales. Las funciones superiores tienen su origen en esta interiorización, en este sentido, las interacciones entre el niño y el adulto (experto) son fundamentales.

Las posiciones dialógicas tienen como punto de partida la obra de Bajtín (1994). Para este autor, el significado no reside dentro de una conciencia individual sino que está determinado por el contexto de uso y está formado por la interacción de diferentes voces. La palabra es un territorio compartido entre quien la pronuncia y quien la recibe, en este sentido, el significado es dialógico, ya que refleja el intento de los escritores de equilibrar sus metas con las expectativas que ellos creen que sus lectores traen al texto. La interpretación literaria y la comprensión es un proceso de negociación entre los "conversantes" en un contexto determinado. La esencia del lenguaje es el diálogo. La escritura, de esta forma, se concibe como un tipo de diálogo cubierto que es analizado y evaluado en términos de los principios de la conversación cotidiana. Bajtín propone que toda escucha/lectura implica una respuesta activa, y que el hablante/escritor está a su vez respondiendo a enunciados anteriores y sabe que su propio enunciado tendrá respuesta. Por lo tanto, la formación de los enunciados tiene un carácter dialógico: al enunciado del que habla le preceden otros enunciados de los que son 
respuesta, y anticipa las respuestas que tendrán después de emitirlo y este carácter dialógico tiene un poder constitutivo en la estructuración y significado del enunciado.

Uno de los principios básicos en la concepción de la educación como proceso de comunicación es el ajuste de la ayuda docente al nivel cognitivo del alumno en un momento determinado, y por tanto, a su Zona de Desarrollo Próximo. La consecución del mejor nivel de apoyo exige del docente el empleo de diversas estrategias comunicativas que han de variar tanto cualitativa como cuantitativamente en cada episodio interactivo y a lo largo de la escolarización. Esta flexibilidad en la regulación del proceso de construcción de los alumnos es un aspecto clave para guiar a los alumnos en la construcción del conocimiento (Díez Vegas et al., 1999). En otras palabras, el éxito o el fracaso del proceso educativo no depende del alumno ni del profesor, considerados ambos de modo aislado, sino de la comunicación mantenida entre ambos.

Desde esta perspectiva de la educación como proceso comunicativo, consideramos al docente no como mero transmisor de una información, sino como guía de la construcción conjunta del conocimiento. Esta regulación eficaz ha de situarse en el nivel actual del alumno, es decir, en el límite de su competencia, para ayudarle en su crecimiento cognitivo. Esto implica el ofrecimiento de la información contingente a su nivel, descartando aquella ya conocida por el alumno y presentando aquella oportuna para que el niño alcance el límite de su desarrollo potencial (Olson, 1994). Expresado en términos vygotskianos, la educación ha de situarse en la Zona de Desarrollo Próximo del alumno. Analizando los diferentes niveles de apoyo docente en el desarrollo de una actividad grupal podemos diferenciar entre la ausencia de intervención del adulto; la solicitud de una respuesta sin ofrecer pistas que faciliten su resolución, el ofrecimiento de diversas estrategias eficaces y la solución directa de la tarea (Diuk, 2007). Estos diferentes actos conversacionales muestran una graduación de la ayuda de menor a mayor nivel; del ajuste de este apoyo a las necesidades del alumno dependerá la correcta comunicación entre el profesor y el niño, y por consiguiente la calidad del proceso de enseñanza-aprendizaje. Ante la importancia de la regulación del apoyo docente y la escasa investigación en torno a ello, principalmente en Educación Preescolar, el presente artículo analiza este aspecto educativo ofreciendo diversos segmentos discursivos que muestren la construcción conjunta del conocimiento (Tolchinsky, 1995).

Tabla 1: Nivel de Apoyo Docente

\begin{tabular}{|c|c|c|c|}
\hline Inexistente & Bajo & Medio & Alto \\
\hline No Intervención & \multicolumn{2}{|c|}{ Estrategias } & Solución \\
\hline \multirow{2}{*}{$\begin{array}{l}\text { El docente no } \\
\text { interviene }\end{array}$} & $\begin{array}{l}\text { Demandas: } \\
\text { no informativa }\end{array}$ & $\begin{array}{l}\text { Pistas: } \\
\text { informativas }\end{array}$ & Enseñanza Directa \\
\hline & $\begin{array}{l}\text { "¿Y ahora qué } \\
\text { letra va?" }\end{array}$ & $\begin{array}{l}\text { "¿Qué letra va } \\
\text { ahora? Feliciiii" }\end{array}$ & "Ahora la I" \\
\hline
\end{tabular}

Fuente: Díez Vegas, 2002. 
En la lectura de la tabla precedente puede reconocerse los diferentes comportamientos que nosotros docentes manifestamos diariamente en el trabajo cotidiano con los alumnos. De hecho, todos variamos el nivel de apoyo en la conversación con ellos, aunque no seamos plenamente conscientes de hacerlo (Zucchermaglio, 1992). Sin embargo, para los educadores, esta reflexión es básica si queremos situarnos en la Zona de Desarrollo Próximo del alumno, lugar donde se construye el conocimiento bajo la ayuda eficaz de alguien más capaz (Kozulin, 1994). Una pregunta clave se nos plantea ahora: ¿cómo saber cuál es la Zona de Desarrollo Próximo del alumno, teniendo en cuenta que ésta varía tras cada aprendizaje, por pequeño que este sea? La conoceremos en la conversación que mantengamos con ellos, y será entonces cuando adaptaremos nuestra ayuda a la respuesta previa del niño. De tal forma, que si puede resolver la actividad por sí mismo, podremos dejarle solo (no intervención); en el caso de que tan sólo requiera un ligero apoyo le podremos plantear una pregunta no informativa (demanda); si precisa un mayor soporte le ofreceremos información que le ayude a llevar a cabo la tarea (pista); y si consideramos que requiere una respuesta concreta, se la ofreceremos (enseñanza directa de la solución). Un breve ejemplo de cada uno de estos niveles de ayuda lo hemos presentado en la Tabla 1. Si bien es cierto que una oportuna intervención docente no es tarea fácil, no es menos cierto que de ella depende el éxito del proceso educativo. Por esta razón es clave en la formación de maestros como guías en la construcción del conocimiento compartido (Mercer, 1997).

\section{Metodología}

Este artículo parte de una línea de investigación abierta sobre la construcción conjunta del conocimiento a partir de la lectura en grupo, iniciada tras una tesis doctoral centrada en este objeto de estudio en 2005, consolidado por el apoyo en varios proyectos de investigación de 2010 a 2012, que se extiende hasta el día de hoy. Se abordan los procesos interactivos en las situaciones de aprendizaje que plantea la maestra bajo un enfoque constructivista. Para ello, hemos grabado trimestralmente en el aula a niños de tres a cinco años (primer y segundo cursos del Segundo Ciclo de Educación Infantil) colaborando en la resolución de diferentes tareas lectoescritoras. Los niños eran agrupados en tríadas que variaban según fuese permanente o parcial la presencia de la maestra y según los niveles de lectoescritura de los participantes.

\section{Objetivos}

Describir la evolución de los procesos de construcción conjunta del conocimiento escritor entre una maestra y sus alumnos, cuando resuelven colectivamente diversas tareas planteadas desde el enfoque constructivista y significativo del lenguaje escrito. 
Identificar las formas en que la maestra promueve la comunicación y el desarrollo de estrategias discursivas entre sus alumnos.

Explorar como la maestra modula el tipo de intervención que realiza en función del nivel lectoescritor de sus alumnos y de las características de la tarea.

\section{Muestra}

Este estudio se ha realizado longitudinalmente durante los dos primeros cursos (2008-2010) de dos escuelas públicas de Educación Preescolar en Burgos capital (España), grabando en video doce tríadas de alumnos en cada trimestre, con un total de 72 sesiones recogidas y de 6.567 turnos de conversación, nuestra unidad de análisis. Las dos escuelas están situadas en barrios o distritos de clase media-baja, donde dominan los matrimonios jóvenes de alrededor de 30 años, en las cuatro escuelas hay programas de aplicación de animación a la lectura. En cada clase se observan 6 grupos de 3 niños. La decisión sobre qué niños forman parte de cada grupo se ha delegado a las maestras. Ambas han seguido un criterio de azar, utilizando la lista de clase por orden alfabético. Distintas investigaciones señalan la influencia de la clase social en la comprensión lectora (Peterson, 1992; Borzone 2005), variable que ha sido detectada en el trabajo de inicio (González García, 2005), del que forma parte este trabajo, y que va a ser una de las variables a tener en cuenta para próximos trabajos de esta línea de investigación abierta. No hemos considerado la variable sexo de los niños, por interesarnos el proceso de construcción del conocimiento en general, pero sí apuntamos a diferencias entre niños y niñas, variable a observar en próximos trabajos.

\section{Procedimiento}

Con objeto de analizar las grabaciones recogidas hemos confeccionado inductivamente un sistema de categorías formado por cinco perspectivas de análisis, agrupadas en tres bloques de estudio: a) las fases de la tarea; b) el proceso de generación colectiva de la escritura, c) el proceso argumentativo. Entre las principales aportaciones de esta investigación hemos de destacar, en primer lugar, la elaboración de un sistema de categorías que analiza la alfabetización en colaboración bajo cinco perspectivas de observación, estrechamente vinculadas entre sí, y desde diferentes niveles de análisis dentro de cada una de ellas, ambas características nos han permitido avanzar en nuestro estudio desde una perspectiva más general hasta aquella de mayor nivel de concreción. En segundo lugar, resaltamos la descripción de distintos segmentos discursivos que muestran como se va construyendo el conocimiento escritor entre los participantes (Babbie, 2009). 
Pasamos a analizar detenidamente algunas secuencias discursivas. Comenzaremos nuestra exposición con la enseñanza directa, necesaria en algunas ocasiones en que el alumno pide una respuesta concreta que no podrá alcanzar a través de nuestras preguntas o pistas; continuaremos analizando diferentes pistas que puede ofrecer el maestro, y demandas para guiar en la resolución de la tarea. Por último, ofreceremos alguna secuencia donde se podrá ver como el maestro desaparece para permitir que sean los propios alumnos quienes trabajen de manera autónoma, asumiendo la responsabilidad de la tarea (Díez Vegas, 2002).

\section{Solución}

El docente que aborda la enseñanza de la escritura desde un enfoque constructivista trata de evitar la enseñanza basada en la transmisión de información, pues defiende el principio educativo de que los niños no aprenden simplemente al escuchar una información (Manzi; Flotts, 2008). Por consiguiente, el maestro que se precie de ser constructivista debe estar preparado para guiar al alumno hacia la respuesta correcta, aunque sin ofrecerle directamente ésta (Díez Vegas, 2002). Sin embargo, existen determinadas circunstancias comunicativas donde es necesario ofrecer respuestas claras. Así, por ejemplo, cuando el niño lo solicita expresamente y unas preguntas o pistas no le ayudarían a alcanzar la solución, será el maestro quien debe ofrecérsela. Estas situaciones se dan principalmente cuando el discurso gira en torno a aspectos ortográficos, cuyas reglas son difíciles de descubrir por el propio niño en determinadas circunstancias, como en la pregunta de si Valencia se escribe con la alta o con la baja, y en los objetivos de esa actividad concreta no deseamos abordar el empleo del diccionario. Entonces, ¿qué pistas podemos ofrecer al alumno para responder a su pregunta? En tales circunstancias, la respuesta directa del profesor mostrará su flexibilidad docente, sin esquemas rígidos que le impidan ofrecer una respuesta correcta en el momento adecuado. Así, podemos observar la Secuencia 1: Ofrecimiento de Respuesta Correcta (Cuadro 1), donde el maestro, en primer lugar, trata de saber si alguno de los participantes sabe como escribir Valencia. Una vez conocida su Zona de Desarrollo Actual, les ofrecerá la respuesta correcta, "con Vvvv" unida a una información que forma parte del conocimiento común construido en numerosas situaciones previas donde se ha trabajado el nombre propio, "con la de Verónica", de modo que los alumnos puedan resolver correctamente la tarea con el mínimo soporte docente. 


\section{Cuadro 1 - Secuencia 1: Ofrecimiento de Respuesta Correcta}

\begin{tabular}{|ll|}
\hline Sergio: & $\begin{array}{l}\text { (a Alba:) Vaaa, vaaa, vvv (han acordado escribir Me voy de } \\
\text { vacaciones a Valencia, donde les gustaría ir de vacaciones. Ahora } \\
\text { están discutiendo cómo escribir el nombre de esta ciudad). }\end{array}$ \\
\hline Alba: & Ésa no la sé. \\
\hline Maestro: & (a Adrián) ¿Tú sabes con qué se escribe Valencia? \\
\hline Adrián: & ¿Valencia? (niega) \\
Maestro: & ¿No? (mira a Alba) ¿Tú lo sabes? \\
\hline Adrián: & Con Valencia. \\
\hline Maestro: & Con Vvvv, con la de Verónica. \\
\hline Adrián: & iAh! \\
\hline
\end{tabular}

Fuente: elaboración propia.

Pistas

En la secuencia anterior hemos podido observar un comportamiento directivo por parte del profesor, donde la responsabilidad del alumno es mínima. Veamos a continuación de otras intervenciones docentes que exigen del grupo de alumnos un mayor compromiso. Comenzamos por aquellas que, si bien no ofrecen la respuesta correcta, presentan una información clave en su resolución. Esta aportación informativa, que hemos denominado pista (Díez Vegas et al., 1999), es una estrategia de escritura, como puede ser la estrategia de focalización alargando las sílabas de las palabras para remarcar el sonido buscado ("¿Qué letra va ahora? Felicidadeeeee") o una estrategia de lectura de lo escrito para que el alumno sepa desde dónde continuar ("ya habéis escrito Felicidade. ¿Ahora cuál os falta?). Estas pistas pueden ir insertas bien en una afirmación o bien como parte de una pregunta. Veamos a continuación ejemplos de ambos tipos de estrategias de un nivel medio de apoyo docente en las Secuencias 2 a 6. En la Secuencia 2 (Cuadro 2), encontramos la intervención "Eeees. Es que se lo vamos a decir despacito", donde el maestro focaliza la atención en la primera sílaba de la palabra que van a comenzar a escribir, estupendo. Dicha la estrategia vuelve a repetirla dos veces más, la primera vez tras la intervención de Sergio, que se despista momentáneamente, y la segunda al observar en la respuesta de Eduardo que éste no capta la pista ofrecida, sino que continúa la palabra comenzada por el maestro ("tu-pen-do"). Esto obliga de nuevo al maestro a repetir la focalización ("Ees"), que de nuevo es completada por Eduardo del mismo modo que antes, al no comprender todavía el objetivo del maestro. Vemos aquí que, a pesar de ser generalmente la focalización en una sílaba una eficaz estrategia de escritura para identificar los fonemas y grafemas, no lo es para Eduardo en esta situación. Sin embargo, podemos observar que Iñaki, sin precisar verbalizar esta estrategia diciendo "es-tuuuuu", consigue identificar la letra "u" como representante de toda la sílaba "tu". Es interesante constatar en este fragmento, asimismo, la respuesta claramente silábica de Iñaki. 


\section{Cuadro 2 - Secuencia 2: Pista de Focalización para Facilitar la Resolución de la Actividad}

\begin{tabular}{|ll|}
\hline Maestro: & $\begin{array}{l}\text { Eeees (ya han escrito la E, de la palabra estupendo) Lo vamos a } \\
\text { decir despacito. }\end{array}$ \\
\hline Sergio: & iHala, una puerta! \\
\hline Maestro: & ¿No? Eeees. \\
\hline Sergio: & Tu-pen-do. \\
\hline Maestro: & Ees (intentando que digan despacio la sílaba siguiente). \\
\hline Sergio: & Tu-pen-do. \\
\hline Iñaki: & (con el lápiz en la boca) La U no sé, la U no sé hacerla. \\
\hline Maestro: & (a Javier:) ¿Tú sabes hacer la U? \\
\hline Javier: & (asiente y la escribe). \\
\hline
\end{tabular}

Fuente: elaboración propia.

Hemos visto en la secuencia anterior como la pista del maestro se presenta de modo exclusivo, sin explicitar la continuación del discurso por parte de los alumnos. A continuación se presentan otras secuencias donde esta clave forma parte de una pregunta. En el primer fragmento discursivo (Cuadro 3) los alumnos están buscando un nombre que contenga la letra "l". Una vez encontrado, el maestro centra la atención en el primer fonema, "l", para que puedan comprobar la corrección de su afirmación así como facilitar la búsqueda de la primera letra de este nombre. Por tanto, se ofrece como pista una estrategia de focalización, consistente en un alargamiento del fonema tratado ("Lllaura").

\section{Cuadro 3 - Secuencia 3: Pista de Focalización Insertada en una Pregunta}

\begin{tabular}{|ll|}
\hline Maestro: & ¿Quién tiene en su nombre la lll? \\
\hline David: & Laura. \\
\hline Elena: & Laura. \\
\hline Maestro: & ¿Y cuál es la primera de Lllaura? \\
\hline Adrián: & (coge la L). \\
\hline Maestro: & Muy bien. Muy bien, Adrián. \\
\hline
\end{tabular}

Fuente: elaboración propia.

La Secuencia 4 (Cuadro 4) muestra otra modalidad de pista inserta en una pregunta. Sin embargo, en este fragmento se ofrece un nuevo matiz, al repetir la intervención previa, y desde allí continuar el enunciado presentando una información que facilite la solución requerida. En esta secuencia los niños han decidido escribir "sí, gracias. Me lo como". El maestro repite la letra "a" propuesta por Sergio, quien todavía no se encuentra en la etapa silábica que le permita identificar al menos la primera "i". Por ello, el maestro, tras repetir la intervención de este niño focaliza la atención en la primera vocal 
de la frase, "¿Aquí va la A?" Tú sabrás. Siii" para que puedan observar la incorrección de la propuesta. Sin embargo, el maestro no logra su propósito con esta clave, pues Eduardo confirma su propuesta. Ello provocará en el maestro un reajuste de su nivel de ayuda, que deberá incrementarse para conseguir una respuesta más próxima a la convencionalmente correcta.

\section{Cuadro 4 - Secuencia 4: Repetición de la Intervención Previa y Pista de Focalización}

\begin{tabular}{|ll|}
\hline Sergio: & Yo primero, ¿vale? \\
\hline Maestro: & $\begin{array}{l}\text { Bueno. Pero no lo hagas muy grande para que todo el mundo } \\
\text { pueda escribir un trozo. Sí, gracias, me lo como. }\end{array}$ \\
\hline Sergio: & Pero, pero. \\
\hline NB: & Arriba, arriba. \\
\hline Sergio: & Pero aquí primero. \\
\hline Nb: & Arriba. \\
\hline Sergio: & Pero aquí primero va la A. \\
\hline Maestro: & ¿Aquí va la A?" Tú sabrás. Siií. \\
\hline Sergio: & Sí. \\
\hline
\end{tabular}

Fuente: elaboración propia.

Una nueva modalidad de intervención la podemos encontrar en la Secuencia 5 (Cuadro 5), donde el maestro no sólo repite la intervención previa, sino que además menciona a su autor, deseando continuar el debate, ofreciendo una pista que centre nuevamente la tarea y concediendo una atención remarcada al alumno emisor (Díez Vegas et al., 1999). Así, en este fragmento discursivo, Santi no acepta la letra "i" mayúscula como "i", pues tan sólo conoce este grafema en minúscula, con "un puntito", toma de posición que seguirá manteniendo posteriormente. Tras la intervención de Santi, el maestro centra la atención en la letra móvil I que deben identificar. ("Venga. Felii. Dice Santi que ésa no es la I ¿Ésa es la I o no?"), confirmando mediante el alargamiento de esta letra en "feliii.", que ese fonema es correcto y que el debate debe centrarse en hallar el grafema correspondiente. Dos turnos después el maestro mencionará nuevamente la reafirmación de Santi, pero en este momento no añadirá ninguna estrategia que facilite la discusión, pues considera que este enunciado será suficiente para que los alumnos continúen el debate.

\section{Cuadro 5 - Secuencia 5: Repetición de la Intervención Previa Añadiendo una Pista de Focalización}

(continúa)

\begin{tabular}{|ll|}
\hline Maestro: & ¿Qué letra es esa que tiene Alba? (llama la atención a la clase). \\
\hline Santi: & (intenta coger la letra que está pegando Alba) Déjame. \\
\hline Alicia: & Esta es la I. \\
\hline Santi: & No es la I. Es la "l". Tiene un puntito aquí. \\
\hline Adrián: & (coge una N) Sí, pues mira. Como la de Iñaki. \\
\hline
\end{tabular}


(conclusión)

Maestro: Venga. Felii. Dice Santi que esa no es la I ¿Esa es la I o no?

Alicia: (asiente).

Maestro: $\quad$ Santi dice que no.

Santi: $\quad$ No, porque tiene un, un puntito aquí.

Fuente: elaboración propia.

Hasta ahora, dentro de los enunciados-pista, hemos presentado tan sólo ejemplos de estrategias de focalización que alargan el fonema buscado. Pasamos ahora a analizar otro tipo de pista-estrategia, la solicitud de revisión, en la Secuencia 6 (Cuadro 6), donde el grupo está componiendo la palabra "felicidades". El maestro intenta que lean lo escrito pero ante el rechazo pasivo de David, ofrece un mayor nivel de ayuda, pasando de una solicitud ("¿Aquí qué tenemos puesto?") a una pequeña pista ("Mira. Eva. Aquí pone feli, ¿qué más?"); pista que presenta la lectura de parte de la producción escrita para que sepan como continuar. Ante la respuesta incorrecta de David, el maestro le pregunta si la palabra que desean componer es "felida...", ofreciéndole de este modo una clave desde la sílaba hasta la palabra, que le permita encontrar su error.

\section{Cuadro 6 - Secuencia 6: Pista basada en una Ampliación desde la Sílaba hasta la Palabra que la Contiene}

\begin{tabular}{|ll|}
\hline Maestro: & Espera, espera. No corras ¿Aquí qué tenemos puesto? \\
\hline David: & (mira hacia otro lado). \\
\hline Maestro: & Mira. Eva. Aquí pone feli, ¿qué más? \\
David: & Da. \\
Maestro: & ¿Felida? \\
Elena: & No. \\
\hline
\end{tabular}

Fuente: elaboración propia.

\section{Demandas}

Cualquier pregunta puede actuar como guía del alumno para que resuelva la tarea en un nivel superior al que alcanzaría sin ayuda. Conforme el alumno se muestra más autónomo en la resolución de la actividad, el maestro ha de disminuir su ayuda, presentándole no soluciones ni pistas, sino tan sólo preguntas mínimamente informativas, que desaparecerán cuando el alumno alcance la regulación individual y sea capaz, por tanto, de resolver la tarea por sí solo (Álvarez, 2009). Estas preguntas planteadas por el maestro, en escasas ocasiones, son solicitudes de información genuinas, pues el docente conoce la respuesta a su pregunta ("¿Qué letra va ahora?"). Las preguntas del maestro forman parte de un tipo característico de discurso, el discurso educativo, en el que, curiosamente, quien conoce las respuestas es quien plantea las preguntas. Las solicitudes de información son estrategias comunicativas utilizadas por los maestros, principalmente con niños pequeños, con quienes no tendría ningún sentido una clase magistral transmisora de información. 
Estas estrategias interrogativas, de elevada frecuencia de utilización en los maestros, desempeñan diversas funciones, relacionadas entre sí, que se pueden resumir del siguiente modo (Díez Vegas, 2002):

- Obtener información sobre el nivel real de desarrollo en el que se encuentran los alumnos, lo que permite trabajar en su ZDP y determinar el tipo de ayuda que se le puede ofrecer en cada momento evolutivo.

- Guiar la resolución conjunta del problema hasta que el niño sea capaz de realizarlo por sí solo.

- Permitir al maestro mantener el control constante sobre el conocimiento de los alumnos, asegurándose de que la información es comprendida de manera conjunta. Las demandas pueden solicitar el empleo de diversos tipos de estrategias, como la estrategia de focalización ("dilo despacito"), la estrategia de lectura ("¿Qué habéis puesto ya?") o la de atención a la consigna acordada ("Antes de escribir dime qué vas a poner").

Pasemos a comentar cuatro secuencias que ejemplifican estos enunciados de escaso soporte docente.

En el primero de estos fragmentos discursivos, la Secuencia 7 (Cuadro 7), se presenta una solicitud de la estrategia de recuerdo del texto que se ha acordado escribir, donde los alumnos se han alejado de la tarea al discutir por la goma de borrar. El maestro devuelve de nuevo la atención a la actividad preguntándoles qué están haciendo ("vamos a ver ¿qué estáis poniendo?") La atención a la consigna es la primera estrategia que se debe utilizar al comenzar a escribir. Una vez presente ya podrán identificar los fonemas y grafemas correspondientes.

\section{Cuadro 7 - Secuencia 7: Demanda de Texto Acordado en la Frase a Escribir}

\begin{tabular}{|ll|}
\hline & $\begin{array}{l}\text { Mira ¿Os habéis puesto de acuerdo, no? Estáis rompiendo la } \\
\text { goma. (le quita la goma a Oscar y la pone en la mesa) La estáis } \\
\text { dejando chiquitita de tanto romperla en cachos (descubre el } \\
\text { trozo de Oscar y hace lo mismo) iOtro! iOye! ¿Pero por qué } \\
\text { rompéis la goma? }\end{array}$ \\
\hline Óscar: & La ha roto Juan. \\
\hline Maestro: $\quad$ Me da igual quien haya sido. Vamos a ver ¿Qué vais a poner? \\
\hline Óscar: & El pollito sale del huevo. \\
\hline Maestro: & Pues venga, empezad. \\
\hline
\end{tabular}

Fuente: elaboración propia.

En la Secuencia 8 (Cuadro 8), encontramos nuevamente una demanda del maestro, en esta ocasión solicitando la estrategia de lectura de lo escrito hasta este momento. En esta actividad el grupo está componiendo con letras móviles la frase "Feliz Navidad". Una vez colocadas las dos primeras letras el 
maestro les pregunta qué han escrito hasta entonces, pues sólo de este modo pueden continuar su producción gráfica. Esta actuación docente es debida a la dificultad de los alumnos en leer su propio texto escrito. Ante el dominio lectoescritor que presentan los niños en este período escolar, el profesor considera conveniente que sean los propios alumnos quienes lean su producción, para hacerles conscientes de la eficacia de la revisión en el proceso de escritura.

\section{Cuadro 8 - Secuencia 8: Demanda de Revisión de lo Escrito}

\begin{tabular}{|ll|}
\hline David: & (pega la E). \\
\hline Maestro: & A ver ¿Qué hemos puesto ahí ya? \\
David: & Fee. \\
\hline Maestro: & Fee ¿Ahora cuál va? \\
Iñaki: & Li, la I. \\
Maestro: & La I? Mira a ver. \\
\hline David: & Sí. \\
\hline Iñaki: & (coge la I y va a ponerle cola). \\
\hline
\end{tabular}

Fuente: elaboración propia.

Dentro de las estrategias de demanda, una nueva modalidad la encontramos en la Secuencia 9 (Cuadro 9), donde los alumnos discuten la direccionalidad de la escritura al comienzo de la segunda línea. En este fragmento el maestro repite la intervención de Adrián, con el fin de mejorar su expresión lingüística y de presentar su contenido más claro al resto de sus compañeros. En esta ocasión, la estrategia reformuladora de la petición previa, acompañada de una pregunta, tiene el objetivo de proseguir el discurso ("¿Y dónde va la primera?") una vez devuelto al grupo el enunciado anterior correctamente verbalizado.

\section{Cuadro 9 - Secuencia 9: Reformulación de la Intervención Anterior}

\begin{tabular}{|ll|}
\hline & $\begin{array}{l}\text { A ver. Diles por qué tú crees, diles por qué tú crees que va ahí. } \\
\text { Ahora no la pegues. A ver. Tú crees que va aquí, ¿no? Diles por } \\
\text { Maestro: }\end{array}$ \\
& $\begin{array}{l}\text { qué (están discutiendo desde dónde continuar escribiendo la } \\
\text { segunda línea, si desde la izquierda o desde la derecha). }\end{array}$ \\
Adrián: & $\begin{array}{l}\text { Porque la, cuando acaba de escribir, siempre en la primera. } \\
\text { Maestro: }\end{array} \quad \begin{array}{l}\text { Ah. Cuando acabas de escribir ahí, hay que ponerlo siempre } \\
\text { donde la primera ¿Y dónde va la primera? }\end{array}$ \\
Santi: & Aquííí (señala al principio, pero de la línea ya escrita). \\
\hline
\end{tabular}

Fuente: elaboración propia.

Otro interesante movimiento conversacional de demanda lo encontramos en la Secuencia 10 (Cuadro 10), donde la repetición del enunciado precedente cumple una importante función: ofrecer a los participantes la posibilidad de proseguir la elaboración de la intervención, mostrando los diferentes puntos de vista. En este segmento discursivo el 
grupo ha decidido escribir el nombre de Iván. Sergio, en desacuerdo con Alicia ("Nn") propone escribir la letra A después de las letras "IV". El maestro repite esta propuesta sometiéndola a debate y dirigiéndose principalmente a Alba ("¿Va la A, Alba?"), quien, no habiendo alcanzado todavía la etapa silábico-alfabética, defendía escribir una N. Una vez mostrado su acuerdo con la vocal propuesta el maestro les anima a escribirla sin más dilación.

\section{Cuadro 10 - Secuencia 10: Repetición del Enunciado Previo sin Añadir Nueva Información}

\begin{tabular}{|ll|}
\hline Alicia: & (escribe la letra I). \\
\hline Maestro: & Iii. \\
\hline Adrián: & La V (escribe). \\
\hline Sergio: & I-va. \\
\hline Alicia: & (a el maestro:) Nn. \\
\hline Maestro: & A mí no me digas nada. Díselo a tus compañeros. \\
\hline Adrián: & (señalando) Ivann no no no. \\
\hline Maestro: & (ríe) ¿Qué letra va ahora? A ver. \\
\hline Sergio: & I-va. La A. \\
\hline Maestro: & ¿Va la A, Alba? \\
\hline Alicia: & Iván A. \\
\hline Adrián: & Iván. \\
\hline Maestro: & (a Alba:) Venga, venga. Que no tenemos toda la mañana. \\
\hline Alicia: & (escribe). \\
\hline
\end{tabular}

Fuente: elaboración propia.

\section{No intervención}

En el modelo tradicional de instrucción, es habitual presentar el aprendizaje como un proceso en que el profesor presenta la información, el alumno la recibe, y el docente comprueba con posterioridad si se ha producido el aprendizaje. En dicha perspectiva, el alumno es concebido prioritariamente como un receptor de conocimientos, y el profesor muestra una elevada frecuencia de intervención. En contraste con tan alto grado de participación docente, en la perspectiva constructivista de la lectoescritura estamos interesados en conceder autonomía a nuestros alumnos, siendo ellos los auténticos protagonistas en las diferentes actividades. A medida que los niños adquieren un mayor dominio lectoescritor y de trabajo en grupo, el maestro puede disminuir el número de sus intervenciones y no sólo el nivel de ayuda en éstas. E incluso puede llegar a desaparecer su soporte verbal durante intervalos temporales de mayor o menor amplitud. Presentaremos, por tanto, secuencias con diversos turnos de palabra 
consecutivos sin ninguna contribución del profesor, mostrando como los alumnos han sido capaces de apropiarse del objetivo docente.

Una importante pregunta se nos plantea ahora: cómo lograr esta participación autónoma entre los propios niños de tan temprana edad. Esto no es posible sin una necesaria fase de aprendizaje, donde los profesores aprendam a hablar menos y los niños aprendan a hablar más... y entre ellos. No es una tarea fácil, pues incluso para los docentes más comprometidos en semejante aventura, entraña una profunda dificultad el replanteamiento de su papel como sujeto que ha de pasar a un segundo plano e incluso llegar a desaparecer. Así lo podemos observar en la Secuencia 11 (Cuadro 11), donde al maestro le cuesta no sólo que presten atención, sino que permanezcan físicamente presentes.

En esta sesión de trabajo vemos como la atención infantil está muy dispersa y se obtienen respuestas al azar, sin tan siquiera mirar a la tarea, llegando a abandonar la actividad sin haberla finalizado. En este fragmento los alumnos de tres años escolarizados en el primer trimestre han de colocar letras móviles para componer el nombre propio de Gaspar, rey mago elegido por ellos, copiando el modelo que se les ofrece. Aquí podemos observar la lucha del maestro para que sus alumnos se concentren en la actividad. A pesar de la insistencia en que piensen antes de actuar, podemos observar como Óscar hace caso omiso de las advertencias y coloca la letra móvil donde él quiere. Ante tal comportamiento, el profesor trata de involucrar a los compañeros para crear una situación de debate ("Iñaki, mira a ver si estás de acuerdo"), pero como éste no está interesado en ello ofrece una respuesta afirmativa de compromiso (con desgana: "Sííi"). Tras la insistencia del tutor, Iñaki por fin se decide a pensar y da la respuesta correcta (observando el modelo: "No. Va aquí"). Mientras tanto, Óscar desea dejar el grupo, en el que de ninguna manera se siente involucrado ("hasta mañana"). El maestro intenta retenerle ("Espera, espera. Mira a ver cuál va ahora"), aunque sin éxito. Mientras, David coloca otra letra sin observar el modelo. Podemos observar en esta secuencia la dificultad de los pequeños para trabajar en una actividad grupal, por lo que puede parecer irrisorio el plantearse una interacción autónoma, coordinando sus puntos de vista sin la intervención docente.

\section{Cuadro 11 - Secuencia 11: Dificultad de los Alumnos para Prestar Atención a la Tarea Colectiva}

(continúa)

\begin{tabular}{|ll|}
\hline Maestro: & $\begin{array}{l}\text { Que no has mirado el nombre. Espera. Así (las ordena) Mira a } \\
\text { ver si esa ahora la puedes poner. Mira a ver si la puedes poner o } \\
\text { no. A ver dónde la vas a poner. Piensa. }\end{array}$ \\
\hline Óscar: & Esta va aquí. \\
Maestro: & $\begin{array}{l}\text { ¿Sí? Pero está ahí, está ahí ¿No la ves que ya está? Mira, ya está } \\
\text { ahí. }\end{array}$ \\
\hline Óscar: & (a pesar de lo que le dice, la coloca). \\
\hline Maestro: & Iñaki, mira a ver si estás de acuerdo. \\
\hline Iñaki: & (se vuelve y sin mirar, con desgana dice.)Siií. \\
\hline
\end{tabular}




\begin{tabular}{|ll|}
\hline Maestro: & ¿Está ahí bien? \\
\hline Iñaki: & (mira mejor) Noo (señala) Va aquí. \\
\hline Óscar: & Hasta mañana. \\
\hline Maestro: & Espera, espera. Mira a ver cuál va ahora. \\
\hline Óscar: & (se marcha sin mirar). \\
\hline David: & (coloca otra letra sin fijarse en el modelo). \\
\hline
\end{tabular}

Fuente: elaboración propia.

En contraste, en la Secuencia 12 (Cuadro 12), podemos observar como, tan sólo un año después de la secuencia anterior, en el primer trimestre del segundo curso de Educación Infantil, la comunicación entre los componentes del grupo se encuentra regulada por el maestro, y en esta ocasión de manera muy fluida y con fuerte implicación de todos los participantes. En esta tarea están componiendo con letras móviles "Feliz Navidad". Hasta el momento han pegado los grafemas F y E, y el maestro les pide que los lean para saber cómo continuar. Ante la respuesta silábica de Iñaki proponiendo la letra "i" para representar la sílaba "li", el maestro le pide que compruebe su respuesta, siendo David quien responde, por haber tomado conciencia de la tarea como una actividad grupal. Nuevamente, el tutor desea volver sobre la respuesta silábica, pretendiendo que ésta sea alfabética e identifique la consonante "f". Para ello, intenta crear un debate ("Vamos a ver. Iñaki ¿Quieres esperarte y hablar con tus compañeros? A ver ¿Cuál va ahora?") David continúa focalizando su atención en la letra "i" ("feliiii"), intervención que continúa Iñaki reafirmando su respuesta vocálica. Sin embargo, Eduardo intenta pronunciar despacio la palabra en cuestión ( Fell, feul, felll). Iñaki, sin escuchar la estrategia mostrada por su compañero, continúa manteniendo su postura, ahora expresamente ante ellos ("la I"). Resulta de enorme interés observar como Sergio, prescindiendo de la mediación docente, responde directamente a la intervención de su compañero verbalizando la respuesta correcta ("No. La ul") y cogiendo la letra "l". Aprovechando esta respuesta, el maestro solicita a Eduardo que explique a sus compañeros por qué va la "l" y no la "i". Es de destacar la importancia de esta estrategia interactiva ("pero tú explícales a tus compañeros por qué crees que va la l. Explícaselo por qué"), donde se solicita que la explicación vaya dirigida a los compañeros, con el fin de descentralizar su actuación hacia la interacción entre los alumnos, mecanismo muy eficaz para lograr una progresiva emancipación de los pequeños. Ante la demanda de explicación, Eduardo presenta un énfasis fonético, pero curiosamente incorrecto ("Feliiiz"). Este alumno ha sabido llegar a la solución, pero no ha sido capaz de explicar cómo pues esta operación supone un mayor nivel cognitivo para el que todavía no se encuentra preparado. Para conducirle hacia dicho nivel, el maestro vuelve a insistir en la necesidad de una explicación ("Explícale por qué"). Por fin, Eduardo se detiene en el fonema correcto ("Feulll"). 


\section{Cuadro 12 - Secuencia 12: Debate entre los Compañeros con Mediación del Profesor}

\begin{tabular}{|c|c|}
\hline Maestro: & A ver ¿Qué hemos puesto ahí ya? \\
\hline David: & Fee. \\
\hline Maestro: & Fee ¿Ahora cuál va? \\
\hline Iñaki: & Li, la I. \\
\hline Maestro: & ¿La I? Mira a ver. \\
\hline David: & Sí. \\
\hline Iñaki: & (coge la I y va a ponerle cola). \\
\hline Maestro: & $\begin{array}{l}\text { Vamos a ver. Iñaki (le quita la letra y el pegamento) ¿Quieres } \\
\text { esperarte y hablar con tus compañeros? A ver ¿Cuál va ahora? }\end{array}$ \\
\hline David: & Feelii. \\
\hline Iñaki: & Nos toca la $I$ (a sus compañeros). \\
\hline Sergio: & ¿La I? (pensando) Felll, feul, felll. \\
\hline Iñaki: & La I (a sus compañeros). \\
\hline Sergio: & No. La ul (coge la L). \\
\hline Maestro: & $\begin{array}{l}\text { Pero tú explícales a tus compañeros por qué crees que va la } l \text {. } \\
\text { Explícaselo por qué. }\end{array}$ \\
\hline Sergio: & Feliiz. \\
\hline Maestro: & Explícale por qué. \\
\hline Sergio: & Feulll. \\
\hline
\end{tabular}

Fuente: elaboración propia.

Tras este relevante progreso desde un desinterés por la tarea (Cuadro 11) hasta un pequeño debate mediado por el maestro con breves secuencias conversacionales de alumno a alumno, seguiremos avanzando hasta la presentación de auténticas secuencias de discurso autónomo, como la presentada en la Secuencia 12 (Cuadro 12). En ella observamos a la tríada de alumnos colaborando en la construcción de la palabra "felicidades" con letras móviles. Eduardo comienza su intervención pegando la letra L, una vez que se la ha quitado a su compañero. Desde ahí, el mismo lector puede contar el número de intervenciones seguidas y conectadas entre sí, llegando incluso Iñaki a consultar a sus compañeros, uno por uno ("¿Tú cuál crees?"). Asimismo, podemos observar un desacuerdo de David, acompañado de un argumento que lo justifica ("Ha puesto la I, y así no es feliz navidaa"), logrando convencer a Sergio, aunque este rectifique dos turnos después ("Noo. Feliiz. La I"). Tras la intervención docente, tratando de facilitar la discusión, comienza un nuevo segmento discursivo regulado por el maestro, donde se intercalan algunos enunciados consecutivos de los niños, presentando nuevamente, en la última parte de esta conversación, una interesante secuencia conversacional autónoma. Resulta clave observar esta secuencia donde, los mismos niños que en el comienzo de la escolaridad 
se mostraban incapaces de escuchar ni tan siquiera a su maestro, gozan ahora, tan sólo un año después, del suficiente grado de autonomía como para discutir entre ellos un significativo número de turnos conversacionales sin recurrir a la mediación docente.

\section{Conclusiones}

En el contexto educativo donde el profesor concibe la enseñanza como una mera transmisión de conocimientos, se considera al alumno un receptor pasivo de la instrucción. Por el contrario, cuando se parte del alumno como alguien que toma parte activa en su aprendizaje, la construcción conjunta del conocimiento puede ser negociada con mayor libertad (Weston, 2009). En esta concepción educativa se crean situaciones de discusión donde surgen diferentes puntos de vista que pueden ser aceptados o rebatidos por los demás participantes, constituyendo la argumentación el medio más eficaz para su resolución (Álvarez, 2009).

Hemos comenzado situándonos en una concepción de la educación como proceso de comunicación entre un profesor y sus alumnos y de éstos entre sí. Desde esta perspectiva el éxito o el fracaso de la educación no se encuentra ni en el profesor ni en los alumnos, considerados de forma aislada, sino en el discurso que se establece entre ellos y que permite o dificulta la construcción conjunta del conocimiento (Álvarez, 2009). En este proceso comunicativo recobra una especial importancia el papel del maestro, no como transmisor de conocimientos, sino como guía de los alumnos en su Zona de Desarrollo Próximo. En dicha Zona el docente ha de promover el aprendizaje de sus alumnos, ofreciendo diversos grados de apoyo contingente con el nivel cognitivo del alumno; cuanto mayor sea la información ofrecida menor será la responsabilidad concedida al alumno, y viceversa (Borzone, 2005). Consiguientemente, en el proceso comunicativo es básico el tipo de ayuda ofrecida por el profesor, que ha de situarse en la Zona de Desarrollo Próximo del alumno, retándole con desafíos intelectuales que supongan cierta dificultad, pero superables, y ofreciéndoles el apoyo necesario en el continuo esfuerzo por resolver la actividad planteada (Kozulin, 1994). Si el nivel de exigencia supera la capacidad del alumno para hacer frente a la actividad y no se le ofrece la información necesaria, el alumno no podrá resolverla con éxito, lo que irá en decremento de su autoestima. Por otra parte, si el reto se sitúa en su Zona de Desarrollo Actual, ofreciéndole información redundante, la resolución de la tarea planteada no significará ningún progreso para el alumno. Por consiguiente, el profesor ha de situarse en el límite de destreza del aprendiz, donde pueda tener lugar un máximo progreso por parte de éste. En la participación comunicativa conjunta de la actividad, el profesor evaluará el nivel del alumno y decidirá el ajuste de la cantidad de información ofrecida, que incrementará si no logra resolver con éxito la tarea, y disminuirá si resultó redundante. De este modo, cederá progresivamente la responsabilidad al grupo de alumnos, hasta lograr que éstos resuelvan la actividad de manera 
autónoma. La intervención docente puede ir desde un ofrecimiento de la respuesta correcta, estilo discursivo propio de una clase magistral pero infrecuente en el trabajo con niños pequeños, hasta el planteamiento de preguntas carentes de información. Avanzando desde un menor a un mayor grado de participación de los alumnos, hemos clasificado la actuación docente en cuatro grandes bloques (Díez Vegas, 2002):

1. Solución: el profesor ofrece directamente la solución a la tarea ("Valencia se escribe con la V").

2. Pista: el maestro ofrece una estrategia que facilite la resolución de la tarea ("¿Qué letra va ahora? Felicidadeeeees").

3. Demanda: se plantea una pregunta que guíe la actividad de un modo general, pero sin ofrecer ninguna información ("¿Qué letra va ahora?").

4. No intervención: el maestro concede el protagonismo a los alumnos, quienes han de gestionar su propio aprendizaje. Como consecuencia de esta autonomía de los alumnos, encontramos numerosas secuencias discursivas entre éstos, sin la mediación docente.

De las estrategias presentadas en esta clasificación, en el estilo docente de un profesor constructivista, debe predominar el ofrecimiento de estrategias que faciliten la actividad que se está realizando, y no la presentación de soluciones a la tarea que no permitan al niño la reflexión en la actividad. No obstante, un buen profesional de la educación debe caracterizarse por la flexibilidad que le permita regular su mayor nivel de apoyo en función de las respuestas obtenidas en la conversación con sus alumnos (Pontecorvo; Orsolini, 1992).

La progresiva autonomía de los alumnos es uno de los grandes objetivos de la educación. Aunque esta participación se ha de incrementar a lo largo de la escolarización, no se logrará la emancipación de la tutela docente a menos que la interacción se dirija a los compañeros y no al profesor (Tolchinsky, 1993). Por ello se ha destacado la necesidad de redirigir la intervención nuevamente al grupo ("explícaselo a tus compañeros"). Si bien resulta difícil la colaboración entre iguales, hemos ofrecido algún segmento discursivo mostrando que es posible encontrar en la interacción de niños de Educación Básica secuencias de conversación autónoma de relativa longitud, dirigiéndose unos a otros y conectando las intervenciones entre sí (Rogoff; Toma, 1997). Para lograr estas secuencias alumno-alumno-alumno, superadora de la interacción maestro-alumno-maestro, es necesario crear un clima de diálogo donde el niño aprenda a intervenir espontáneamente... y el profesor a no hacerlo. Esto no es una tarea fácil, como reconocen los maestros que favorecen el trabajo en pequeño grupo, pues implica un profundo replanteamiento del papel docente, cuyo protagonismo ha de verse seriamente reducido. A la luz de lo expuesto, podemos concluir que:

- Las estrategias de enseñanza observadas integran modelos de producción escrita flexibles y funcionales que se complementan entre sí, apoyándonos, también, en teorías metacognitivas (Manzi; Flotts, 2008). 
- En todos los casos, será necesario que las tareas de escritura estén encuadradas en una situación comunicativa concreta y tengan un propósito determinado, a fin de que el alumno sea consciente de la pertinencia e importancia de emitir su mensaje en un contexto sociocultural específico. Algo que se facilita si encuadramos la escritura en un proyecto interdisciplinario (Álvarez, 2009).

- No es conveniente ser rígido en la enseñanza de las estrategias, pero sí desarrollar la tarea de enseñanza-aprendizaje-evaluación en forma sistemática e intensiva (Ortega, 2005).

- La práctica de las estrategias debe tener un carácter gradual. Es decir, disponer la situación de aprendizaje de modo que la estrategia se practique en primer lugar sobre tareas más sencillas, para posteriormente evolucionar hacia tareas más complejas (Fernández; Melero, 1995).

- El éxito en la aplicación de este o de cualquier modelo está en estricta relación con el carácter de las intervenciones didácticas y, fundamentalmente, con el logro de un entendimiento interpersonal profesor/alumno, en la relación dialógica (Lacón; Ortega, 2008).

En resumen, en este trabajo se elabora una clasificación de los diferentes niveles de ayuda docente en función de la Zona de Desarrollo Próximo del alumno. Este análisis se ha apoyado en diversas secuencias discursivas basadas en una situación real de interacción de diferentes tríadas de alumnos de Educación Preescolar o Infantil con su profesor. La sistematización, unida a los segmentos discursivos, ha permitido reflexionar explícitamente sobre la regulación del apoyo que nosotros, maestros, prestamos a nuestros alumnos en su proceso de construcción del conocimiento.

\section{Bibliografía}

ÁLVAREZ, P. Competencia en comunicación lingüística. Valencia: Generalitat Valenciana, 2009.

ARROYO, G.; MATIENZO, T. Pensar, decir, argumentar: lógica y argumentación desde diferentes perspectivas disciplinares. Buenos Aires: Prometeo Libros, 2011.

BABBIE, E. R. The practice of social research. 12. ed. Wadsworth: Cencage Learning, 2009. p. 436-440.

BAJTIN, M. M. El método formal en los estudios literarios: introducción crítica a una poética sociológica. Madrid: Alianza, 1994.

BAKEMAN, R.; GOTTMAN, J. M. Observing interaction: an introduction to sequential analysis. 2. ed. New York: Cambridge University Press, 1997. 
BORZONE, A. La lectura de cuentos en el jardín infantil: un medio para el desarrollo de estrategias cognitivas y lingüísticas. Psykhe, Santiago, v. 14, n. 1, p. 192-209, mayo 2005.

DÍEZ VEGAS, C. La interacción social y la construcción del conocimiento en el inicio lectoescritor: un estudio longitudinal. 2002. Tesis (Doctoral) Universidad Nacional de Educación a Distancia, Madrid, 2002.

DÍEZ VEGAS, C.; PARDO, P. Curso de experto universitario en lenguaje escrito en educación infantil: estrategias de trabajo en grupo. Madrid:

Uned, 2000.

DÍEZ VEGAS, C.; PARDO, P.; LARA, F.; ANULA, J. J.; GÓNZALEZ, L. La interacción en el inicio de la lectoescritura. Madrid: Ministerio de Educación y Cultura/CIDE, 1999.

DIUK, B. El aprendizaje inicial de la lectura y la escritura de palabras en español: un estudio de caso. Psykhe, Santiago, v. 16, n. 1, p. 27-39, mayo 2007.

FERNÁNDEZ, P.; MELERO, A. (Ed). La interacción social en contextos educativos. Madrid: Siglo XXI, 1995.

FERREIRO, E. Desarrollo de la alfabetización: psicogénesis. In:

GOODMAN, Y. M. Los niños construyen su lectoescritura. Buenos Aires: Aique, 1991.

FRADE, L. Desarrollo de competencias lectoras y obstáculos que se presentan. México: Inteligencia Educativa, 2009.

GONZÁLEZ GARCÍA, J. Análisis de la construcción conjunta del conocimiento en los debates postnarrativos: estudio comparativo en dos estilos docentes a lo largo del último curso de educación infantil. 2005. Tesis (Doctoral) - Universidad de Burgos, Burgos, 2005.

KOZULIN, A. La psicología de Vygotsky. Madrid: Alianza Editorial, 1994.

LACON, N.; ORTEGA, S. Cognición, metacognición y escritura. Signos, v. 41, n. 67, p. 231-255, 2008.

LO CASCIO, V. Gramática de la argumentación: estrategias y estructuras. Madrid: Alianza, 1998.

MANZI, J.; FLOTTS, M. Medición de habilidades de comunicación escrita: hallazgos y proyecciones. In: COLOQUIO DE INVESTIGACIÓN MIDE UC, 2008, [S. 1.]. [Actas. . .]. Disponible en: <http://www.mideuc.cl/libroed/ pdf/La_Evaluacion_Docente_en_Chile.pdf $>$. Accesso en: 06 jun. 2015. 
MARUNY, L. L.; MINISTRAL, M.; MIRALLES, M. Escribir y leer: materiales curriculares para la enseñanza y el aprendizaje del lenguaje escrito, de 3 a 8 años. Madrid: Edelvives/M.E.C., 1995.

MERCER, N. La construcción guiada del conocimiento: el habla de profesores y alumno. Barcelona: Paidós, 1997.

MÉXICO. Secretaria de Educación Pública. Manual para favorecer el desarrollo de competencias de lectura y escritura. [Ciudad de México]: SEP, 2012.

NEMIROVSKY, M. La integración de contenidos: el papel de lo general y de lo específico: ¿un problema didáctico? In: ARROYO ACEVEDO, M. (Coord.). La atención del niño preescolar. [Ciudad de México]: Instituto Estatal de Educación Pública de Oaxaca/Fundación SNTE para la Cultura del Maestro Mexicano, 1995.

OLSON, D. The world on paper. Cambridge: Cambridge University Press, 1994.

OLSON, D. La escritura y la mente. In: WERTSCH, J. V.; DEL RÍO, P; ÁLVAREZ, A. (Ed.). La mente sociocultural: aproximaciones teóricas y aplicadas. Madrid: Fundación Infancia y Aprendizaje, 1997. p. 77-97.

ORTEGA, S. Proyecto de investigación: la competencia discursiva y metadiscursiva de alumnos que finalizan el primer ciclo de Educación Básica Común y/o su equivalente en educación especial (2002-2005). Mendoza: SECyTP, 2005.

PETERSON, C. Narrative skills and social class. Journal of Child Language, Cambridge, v. 19, p. 251-269, 1992.

PETERSON, C. Echoing our parents: parental influences on children's narration. In: PRATT, M. W.; FIESE, B. H. (Ed.). Family stories and the life course: across time and generations. Mahwah: Lawrence Erlbaum Associates, 2004. p. 27-54.

PONTECORVO, C.; ORSOLINI, M. Analizando los discursos de las prácticas alfabetizadoras desde la perspectiva de la teoría de la actividad. Infancia y Aprendizaje, [Madrid], v. 58, p. 125-141, 1992.

ROGOFF, B.; TOMA, C. Shared thinking: community and Institutional Variations. Discourse Processes, [London], v. 23, p. 471-497, 1997.

SIGNES, S. Jugando a pensar: una experiencia en educación infantil. Crearmundos, [Barcelona], 2004. Disponible en: <http://www. crearmundos.net/primeros/Revista/Edicao01/Educacion/Edu_Jugando_ Pensar.htm>. Accesso en: 8 fev. 2014. 
TOLCHINSKY, L. Aprendizaje del lenguaje escrito: procesos evolutivos e implicaciones didácticas. Barcelona: Anthropos, 1993.

VYGOTSKY, L. S. El desarrollo de los procesos psicológicos superiores. Barcelona: Crítica, 1989.

VYGOTSKY, L. S. Pensamiento y lenguaje. Barcelona: Paidós, 1995.

WESTON, A. Las claves de la argumentación. Barcelona: Ariel, 2009.

ZUCCHERMAGLIO, C. Condividire socialmente la convenzionalità della lingua scritta. In: PONTECORVO, C., AJELLO, A., ZUCCHERMAGLIO, C. Discutendo si impara. Roma: La Nuova Italia Científica, 1992.

Javier González García, doutor em Educação pela Universidad de Burgos, é professor e pesquisador na Universidad de Guanajuato, México. jr2000x@yahoo.es

Recebido em 13 de maio de 2014.

Solicitação de correções em 22 de dezembro de 2014.

Aprovado em 29 de janeiro de 2015. 